\title{
INTERPRETIVE STRUCTURAL MODELING OF IDENTIFIED SUCCESS FACTORS TO LEAN IMPLEMENTATION IN SMES
}

\author{
doi: $10.2478 /$ cqpi-2019-0010 \\ Date of submission of the article to the Editor: $28 / 04 / 2019$ \\ Date of acceptance of the article by the Editor: 20/05/2019
}

\author{
Arvind Kumar Shrimali ${ }^{1}$ - orcid id: 0000-0003-4669-5306 \\ ${ }^{1}$ Chameli Devi Group of Institutions, India
}

\begin{abstract}
Lean practices are implemented in manufacturing enterprises to find hidden waste and attain continuous improvement. Various enterprises have experienced benefits owing to the Lean implementation. Following the use of appropriate lean instruments and techniques, there are many factors that affect successful lean implementation process. Researchers have identified a large number of these success factors to implementation of Lean. Understanding these enablers and the interactions between them can be crucial to the success of lean implementation. Interpretive Structural Modeling (ISM) is one of the established methodologies to bring forward the interrelationships among parameters of an issue or a problem. The purpose of this paper is to create the hierarchy of the various success factors to Lean Implementation according to their importance using the approach of ISM to facilitate Small and Medium enterprises (SMEs) across India.
\end{abstract}

Keywords: Lean implementation, Interpretive Structural Modeling (ISM), Critical Success Factors (CSF), Small and Medium enterprises (SMEs)

\section{INTRUDUCTION}

Lean implementation is fast becoming popular across the globe to eliminate the wastes within an organization and thus improve its performance. The concepts: value, waste, and the process of creating value without waste, are captured in the six Lean Principles. Lean strives to create an efficient operation and by bringing together the best practices and concepts of productivity and problem-solving. (Josef, O., 2012).

The importance of SMEs in the Indian economy

Small and Medium-size Enterprises (SMEs) are a critical component of the economy of any country. These companies employ a large percentage of the total work force and contribute with significant proportion of the value creation in economy. SMEs in India contribute significantly to the manufacturing output, in terms of employment provision, value added, and numbers of SMEs. In India the Micro, Small and Medium Enterprises (MSME) sector consisting of 36 million units, as of today, provides employment to over 80 million persons. The Sector through more than 6,000 products contributes about $8 \%$ to GDP besides $45 \%$ to the total manufacturing output and $40 \%$ to the exports from the country. The MSME sector has the potential to spread 
industrial growth across the country and can be a major partner in the process of inclusive growth (MSME at a Glance 2016).

Therefore, it is imperative for the SMEs to be conversant with the key success factors of implementing either Lean. Lean Manufacturing is a collective term for production practices aimed at increasing value creation and reducing waste in all forms. Lean Manufacturing focuses on shortening the timeline between customer order and shipment, as well as cutting costs and improving quality, by identifying and eliminating waste in the value stream. (Bakås, Ottar, Govaert, Tim, Van Landeghem, Hendrik, 2011) It is difficult to move from a traditional production system to a Lean production system. This change demands attention of both the processes and the people involved. The availability of extensive documentation on the benefits of the lean manufacturing implementation could not extend it to a large number of companies. (Department of Education \& Training, 2009).

The present study focuses on the success factors to the implementation of the Lean concept in SMEs in India and to create the hierarchy of the various success factors to Lean Implementation according to their importance using the approach of ISM to facilitate SMEs across India. ISM methodology has been used in this study to understand and analyse contextual relations and hierarchical levels of success factors in the implementation of Lean. Interpretive Structural Modeling (ISM) methodology is being applied to the identified Critical Success Factors based from the base research paper by Bakås, Ottar, Govaert, Tim, Van Landeghem, and Hendrik. The body of this paper is organized as follows. After Introduction in Section 1, the Section 2 presents the literature study on the success factors to implementation of Lean. Section 3 explains the ISM methodology and Section 4 presents the details of the ISM approach to the success factors to implementation of Lean. The discussion on the outcome of the study is presented in Section 5. Section 6 presents the Conclusions.

\section{PAPER STRUCTURE}

A study of currents literature on the interface between Lean, Critical Success Factors and SMEs has been conducted to identify the basic critical success factors to the implementation of Lean in SMEs.

\subsection{Background of Lean Implementation in SMEs}

The Lean manufacturing is a manufacturing strategy that eliminates waste and increases the value of production activities to achieve a smooth flow of production. Without a Lean manufacturing strategy, an organization cannot succeed in today's global competition, where higher quality, faster delivery, and lower costs are needed (N. Nordin, et al., 2010) (Shrimali \& Soni, 2017). In the light of the inherent strengths and weaknesses of MSMEs, the factors responsible for success of implementing Lean need to be explored.

\subsection{Critical Success Factors for adopting Lean in SMEs}

A number of studies have been carried out on implementation of Lean to explore the success factors. (Yamchello et al.2014, Zargun \& Al-Ashaab, 2014).

A combination of comprehensive literature review and visits to ten SMEs based in the East of the UK were employed in the study. (Achanga, P. et al. 2006). Several critical factors that determine the success of implementing the concept of lean manufacturing within SMEs are identified. Leadership, management, finance organisational culture 
and skills and expertise, amongst other factors; are classified as the most pertinent issues critical for the successful adoption of lean manufacturing within SMEs environment. Based on the literature review, a set of areas were identified as potential important factors (Bakas et al., 2011) for succeeding with Lean implementations in SMEs:

- Leadership and management involvement

- Employee involvement and sufficient participation

- Change in organisational culture and the time factor

- Motivation and learning

- Performance evaluation systems

- Communication of goals and objectives with improvement initiatives

- Linking improvement initiatives to business strategy and customers

The Literature survey has thrown light on various factors that ensure successful Lean Implementation.

\section{PROBLEM DESCRIPTION}

The study has taken the research of Bakas et al. (2011) the success factors to the implementation of Lean in SMEs as the base paper for this study. The study mentions This current paper aims to study, understand and analyze the contextual relations and hierarchical levels of success factors in implementation of Lean. The authors have used the interpretive structure modeling (ISM), an established method of identifying relationships between different parameters of the system.

The purpose of this paper is:

1. To identify the most critical success factors associated with the implementation of Lean in SMEs,

2. To determine the relationship between these identified success factors to implementation of Lean by means of interpretive structural modeling,

3. To suggest a structural model for the success factors to Lean Implementation, and

4. To organize the identified success factors in different categories using MICMAC analysis.

\section{SOLUTION METHODOLOGY}

The study has taken the research of Bakas et al. (2011) the success factors to the implementation of Lean in SMEs as the base paper for this study. The study mentions This current paper aims to study, understand and analyze the contextual relations and hierarchical levels of success factors in implementation of Lean. The authors have used the interpretive structure modeling (ISM), an established method of identifying relationships between different parameters of the system.

\subsection{Interpretive Structural Modeling (ISM)}

The Interpretive structural modeling (ISM) is a process of interactive learning. Presence of indirect or direct-connected elements complicates the structure of any system. It is difficult to handle such a system, whose structure is not clearly defined. Therefore, a methodology is needed to identify a structure. Such a method isInterpretive structural modelling. The various components of a process are analyzed in a comprehensive system model. There are many examples of the use of ISM in the research literature. The two basic concepts to understand the ISM system arereachability and transitivity. ISM's basic idea is to use the experts' practical 
experience and expertise to develop a complex system (element) into subsystems (elements) and create a multi-level structural model. The ISM method is the rule and guidance on the complexity of the relationship between the elements of the system elements (J. W. Warfield, 1974)

The various steps in the ISM methodology (A. P. Sage, 1977) are as follows:

Step 1. The variables (criteria) are considered for the system under consideration.

Step 2. Based on the variables identified in step 1, a context relationship between the variables is established to determine which variables are to be examined.

Step 3. The structure of the personalized interaction matrix (SSIM) is developed for the variables, which indicates the pairing relationships between the variables of the evaluated system.

Step 4. The access matrix is developed from SSIM and the matrix transition is verified. The transition of a contextual relationship is a fundamental premise in ISM. It establishes that if variable $A$ is related to $B$ and $B$ is related to $C$, then $A$ is necessarily related to $\mathrm{C}$.

Step 5. The scope matrix obtained in step 4 is divided into different levels.

Step 6. Based on the previous relationships in the availability matrix, an objective graphic is drawn and the transitive links are eliminated.

Step 7. The resulting digraph is converted to ISM by replacing the report node variables.

Step 8. The ISM model developed in step 7 is reviewed to verify the conceptual inconsistency and make the necessary adjustments. The previous steps are illustrated in Figure 1.

\section{APPLICATION OF ISM}

ISM has been used by researchers across the globe to develop a relationship among issues/enablers/barriers in different fields. Usta and Asan (2016) and Shrimali et al. (2018) have analysed the Interactions among the Lean Implementation Barriers.

\subsection{Data collection}

The identified success factors taken under the study are from the base paper by Bakås et. al (2011). These success factors are:

1. Leadership and management involvement

2. Employee involvement and sufficient participation

3. Change in organisational culture and the time factor

4. Motivation and learning

5. Performance evaluation systems

6. Communication of goals and objectives with improvement initiatives

7. Linking improvement initiatives to business strategy and customers

\subsection{Structural self-interaction matrix (SSIM)}

In the first step towards generating a matrix, considering the contextual relationship for each variable, the existence of a relation between any two barriers ( $i$ and $j$ ) and the associated direction of the relation is questioned. Following four symbols are used to depict the direction of a relationship between the barriers ( $i$ and $j$ ):

$\mathrm{V}$ : Factor i will promote factor $\mathrm{j}$;

$X$ : Factor $\mathrm{i}$ and $\mathrm{j}$ will promote each other;

A : Factor $\mathrm{j}$ will promote factor $\mathrm{i}$;

$\mathrm{O}$ : Factor $\mathrm{i}$ and $\mathrm{j}$ are unrelated. 
The SSIM for the barriers in the implementation of green supply chain is given in Table 1. The following section explains the use of the symbols $V, A, X$, and $O$ in the SSIM.

Table 1

Structural Self Interaction Matrix (SSIM)

\begin{tabular}{|c|l|c|c|c|c|c|c|c|}
\hline \multicolumn{1}{|c|}{ i j } & $\mathbf{1}$ & $\mathbf{2}$ & $\mathbf{3}$ & $\mathbf{4}$ & $\mathbf{5}$ & $\mathbf{6}$ & $\mathbf{7}$ \\
\hline 1 & Leadership and management involvement & & $\mathrm{V}$ & $\mathrm{V}$ & $\mathrm{X}$ & $\mathrm{V}$ & $\mathrm{V}$ & $\mathrm{X}$ \\
\hline 2 & Employee involvement and sufficient participation & & & $\mathrm{X}$ & $\mathrm{A}$ & $\mathrm{V}$ & $\mathrm{A}$ & $\mathrm{A}$ \\
\hline 3 & Change in organisational culture and the time factor & & & & $\mathrm{V}$ & $\mathrm{O}$ & $\mathrm{A}$ & $\mathrm{X}$ \\
\hline 4 & Motivation and learning & & & & $\mathrm{O}$ & $\mathrm{A}$ & $\mathrm{A}$ \\
\hline 5 & Performance evaluation systems objectives with improvement & & & & & & $\mathrm{V}$ & $\mathrm{A}$ \\
\hline 6 & $\begin{array}{l}\text { Communication of goals and } \\
\text { initiatives }\end{array}$ & & & & $\mathrm{O}$ \\
\hline 7 & $\begin{array}{l}\text { Linking improvement initiatives to business strategy and } \\
\text { customers }\end{array}$ & & & & & & \\
\hline
\end{tabular}

\subsection{Initial Reachability Matrix}

The SSIM has been converted into a binary matrix, called the initial reachability matrix by substituting $\mathrm{V}, \mathrm{A}, \mathrm{X}$ and $\mathrm{O}$ by 1 and 0 as per the case. This is termed as Initial Reachability Matrix. See Table 2. The substitution of $1 \mathrm{~s}$ and 0 s are as per the following rules:

I. If the $(i, j)$ entry in the SSIM is $V$, the $(i, j)$ entry in the reachability matrix becomes 1 and the $(j, i)$ entry becomes 0 .

II. If the (i, j) entry in the SSIM is $A$, the ( $i, j)$ entry in the reachability matrix becomes 0 and the $(j, i)$ entry becomes 1 .

III. If the (i, j) entry in the SSIM is $X$, the (i, j) entry in the reachability matrix becomes 1 and the (j, i) entry also becomes 1 .

IV. If the ( $i, j)$ entry in the SSIM is $O$, the (i, j) entry in the reachability matrix becomes 0 and the $(\mathrm{j}, \mathrm{i})$ entry also becomes 0 .

Table 2

Initial Reachability Matrix

\begin{tabular}{|c|c|c|c|c|c|c|c|c|}
\hline & $\mathbf{i}$ & 1 & 2 & 3 & 4 & 5 & 6 & 7 \\
\hline 1 & Leadership and management involvement & 1 & 1 & 1 & 1 & 1 & 1 & 1 \\
\hline 2 & Employee involvement and sufficient participation & 0 & 1 & 1 & 0 & 1 & 0 & 0 \\
\hline 3 & Change in organisational culture and the time factor & 0 & 1 & 1 & 1 & 0 & 0 & 1 \\
\hline 4 & Motivation and learning & 1 & 1 & 0 & 1 & 0 & 0 & 0 \\
\hline 5 & Performance evaluation systems & 0 & 0 & 0 & 0 & 1 & 1 & 0 \\
\hline 6 & $\begin{array}{l}\text { Communication of goals and objectives with improvement } \\
\text { initiatives }\end{array}$ & 0 & 1 & 1 & 1 & 0 & 1 & 0 \\
\hline 7 & $\begin{array}{l}\text { Linking improvement initiatives to business strategy and } \\
\text { customers }\end{array}$ & 1 & 1 & 1 & 1 & 0 & 0 & 1 \\
\hline
\end{tabular}

\subsection{Final Reachability Matrix}

After incorporating the transitivity as described in Step 4 of the ISM methodology, the final reachability matrix is shown in Table 3, the driving power and dependence of each variable is also shown. Driving power for each variable is the total number of variables (including itself), which it may help to achieve. On the other hand, 
dependence is the total number of variables (including itself), which may help in achieving it. These driving power and dependencies will be later used in the classification of variables into the four groups of autonomous, dependent, linkage and drivers (independent).

Table 3

Final Reachability Matrix

\begin{tabular}{|c|c|c|c|c|c|c|c|c|c|}
\hline \multicolumn{2}{|r|}{$\mathbf{i}$} & 1 & 2 & 3 & 4 & 5 & 6 & 7 & \multirow{2}{*}{$\begin{array}{c}\begin{array}{c}\text { Driving } \\
\text { Power }\end{array} \\
7\end{array}$} \\
\hline 1 & Leadership and management involvement & 1 & 1 & 1 & 1 & 1 & 1 & 1 & \\
\hline 2 & Employee involvement and sufficient participation & 0 & 1 & 1 & 0 & 1 & 0 & 0 & 3 \\
\hline 3 & $\begin{array}{l}\text { Change in organisational culture and the time } \\
\text { factor }\end{array}$ & 0 & 1 & 1 & 1 & 0 & 0 & 1 & 4 \\
\hline 4 & Motivation and learning & 1 & 1 & 0 & 1 & 0 & 0 & 0 & 3 \\
\hline 5 & Performance evaluation systems & 0 & 0 & 0 & 0 & 1 & 1 & 0 & 2 \\
\hline 6 & $\begin{array}{l}\text { Communication of goals and objectives with } \\
\text { improvement initiatives }\end{array}$ & 0 & 1 & 1 & 1 & 0 & 1 & 0 & 4 \\
\hline 7 & $\begin{array}{l}\text { Linking improvement initiatives to business strategy } \\
\text { and customers }\end{array}$ & 1 & 1 & 1 & 1 & 0 & 0 & 1 & 5 \\
\hline & Dependence Power & 3 & 6 & 5 & 5 & 3 & 3 & 3 & 28 \\
\hline
\end{tabular}

\subsection{Level partitions}

The reachability and antecedent (J.W. Warfield, 1976) for each critical success factor is obtained from the available final matrix. The reachability set for a given variable consists of the variable itself and other variables that it can help achieve. A set of antecedents consists of the variable itself and other variables that can help achieve them. Subsequently, the intersection of these sets is derived for all the variables. The variable for which the reachability and intersection sets are the same is given by the top level variable in the ISM hierarchy that would not help to achieve any other variable above its own level. After identifying the top-level element, the remaining variables are discarded. In this study, 8 critical success factors are presented together with their reachability set, background set, antecedent set and levels, as shown in Table 4. The process of identifying these success factors is completed in eight iterations.

This iteration continues until the levels of each variable are reached. The specified levels help build the digraph and the final ISM model (Fig 1).

Table 4

Iteration table for level partition

\begin{tabular}{|c|c|c|c|c|}
\hline S. No. & Reachability Set & Antecedent Set & Intersection Set & Level \\
\hline 1 & $1,2,3,4,5,6,7$ & $1,4,7$ & $1,4,7$ & I \\
\hline 2 & $2,3,5$ & $1,2,3,4,6,7$ & 2,3 & II \\
\hline 3 & $2,3,4,7$ & $1,2,3,6,7$ & $2,3,7$ & I \\
\hline 4 & $1,2,4$ & $1,3,4,6,7$ & 1,4 & II \\
\hline 5 & 5,6 & $1,2,5$ & 5 & III \\
\hline 6 & $2,3,4,6$ & $1,5,6$ & 6 & III \\
\hline 7 & $1,2,3,4,6$ & $1,3,7$ & 1,3 & II \\
\hline
\end{tabular}




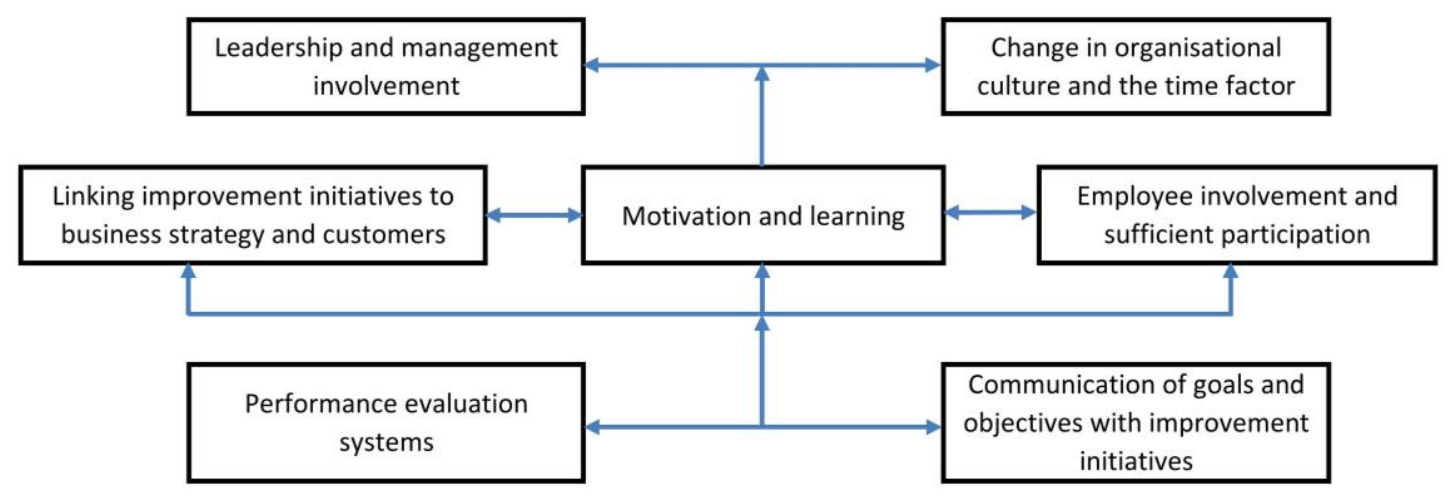

Figure 1 ISM based model for Critical Success factors to lean implementation

\subsection{MICMAC analysis}

Matriced' Impacts croises-multipication applique' and classment (cross-impact matrix multiplication applied to classification) is abbreviated as MICMAC. The MICMAC principle is based on multiplication properties of matrices (H. D. Sharma et al., 1995). The purpose of MICMAC analysis is to analyze the drive power and dependence power of enablers. This is done to identify the key enablers that drive the system in various categories. Based on their drive power and dependence power, the enablers, in the present case, have been classified into four categories as follows:

1. Autonomous enablers: These enablers have weak driving power and weak dependence. They are relatively disconnected from the system, with which they have few links, which may be very strong. These enablers are represented in Quadrant I

2. Dependent enablers: This category includes those enablers which have weak drive power but strong dependence power and placed in Quadrant II.

3. Linkage enablers: These have strong driving power as well as strong dependence and are placed in Quadrant III. They are also unstable and so any action on them will have an effect on others and also a feedback effect on themselves.

4. Independent enablers: These have strong driving power but weak dependence power. These are represented in Quadrant IV.

Table 5 shows the Driving power and dominance diagram for lean success factors.

Table 5

Driving power and dominance diagram for lean success factors

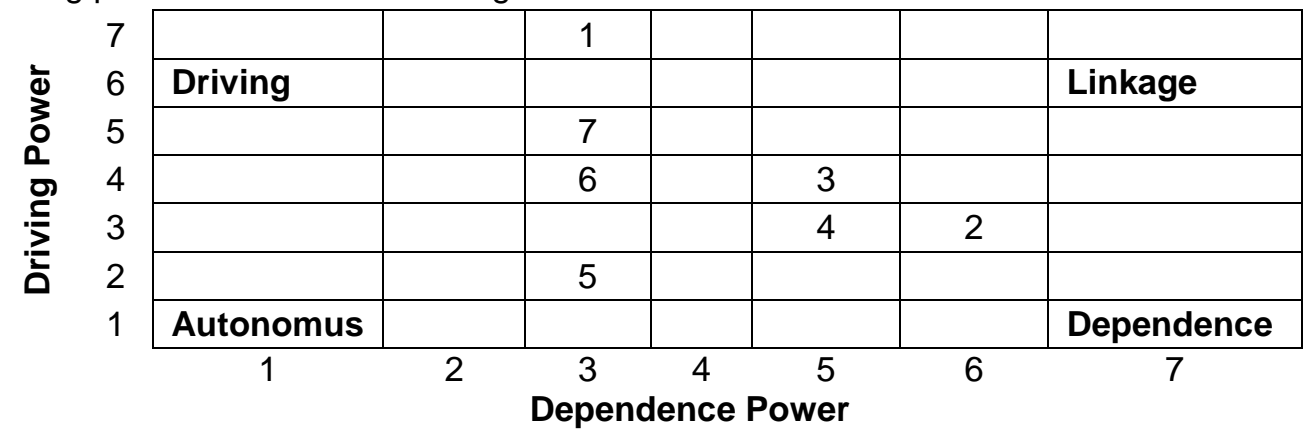

\section{RESULTS AND DISCUSSION}

Autonomous variables generally appear as weak driver as well as weak dependent and are relatively disconnected from the system. These variables do not have much 
influence on the other variables of the system. Performance evaluation systems and Communication of goals \& objectives with improvement initiatives are falling under autonomous variable category and these are linked with each other in the structure. Thus, these are stable factors. While Leadership and management involvement and Linking improvement initiatives to business strategy \& customers are driving the other success factors. Emphasis is needed over these critical success factors to ensure successful lean implementation.

\section{RESULTS AND DISCUSSION}

Autonomous variables generally appear as weak driver as well as weak dependent and are relatively disconnected from the system. These variables do not have much influence on the other variables of the system. Performance evaluation systems and Communication of goals \& objectives with improvement initiatives are falling under autonomous variable category and these are linked with each other in the structure. Thus, these are stable factors. While Leadership and management involvement and Linking improvement initiatives to business strategy \& customers are driving the other success factors. Emphasis is needed over these critical success factors to ensure successful lean implementation.

\section{CONCLUSIONS}

To be more competitive a lean implementation should be well coordinated and responsive.

This paper developed a model to understand the critical success factors to Lean Implementation in SMEs. Although, ample literature is available on lean manufacturing and various issues related to it. The relationship between success factors to lean implementation in SMEs needed to be modelled for manufacturing organizations. The present model will help managers and lean practitioners to understand the relationship in detail. This research assumes significant contribution in this regards.

This study has considered seven success factors. The interpretive structural modeling (ISM) approach has been employed to develop the structural relationship among these success factors. ISM approach helped in determining driving and dependence power of all variables. It is observed that 'Leadership and management involvement, and Linking improvement initiatives to business strategy \& customers' are the major drivers for of lean success factors. Special attention must be paid on these success factors to have proper lean practice.

The present study was aimed to bring forward the contextual relations and hierarchical levels of success factors in the implementation of Lean. This has brought forward the parameters responsible as drive factors among the success factors to the implementation of Lean in SMEs. Linear structural relationship can be developed between these lean success factors so as to test the validity of the success factors of such hypothetical models for future study.

\section{REFERENCES}

Achanga, P., Shehab, E., Roy, R., Nelder, G., 2006. Critical success factors for lean implementation within SMEs. Journal of Manufacturing Technology Management 17(4). DOI: 10.1108/17410380610662889 
Bakås, Ottar, Govaert, Tim, Van Landeghem, Hendrik, 2011. Challenges and success factors for implementation of lean manufacturing in European SMEs, MITIP 2011, Norwegian University of Science and Technology, Trondheim, Norway

Department of Education \& Training, 2009. Lean Networking-A guide to Lean Implementation Networks for small to medium enterprises, New South Wales, Australia. DOI: 10.1051/matecconf/20178702024

Josef, O. (Ed.), 2012. The Guide to Lean Enablers for Managing Engineering Programs, Version 1.0. Cambridge, MA: Joint MIT PMI INCOSE Community of Practice on Lean in Program Management. URI:http://hdl.handle.net/1721.1/70495.

MSME, 2016. MSME at a GLANCE 2016, Ministry of Micro, Small \& Medium Enterprises, available at: msme.gov.in/sites/default/files/MSME_at_a_GLANCE_2016_Final.pdf fetched on 1 May 2017.

Nordin, N., Deros, B.M., and Wahab, D. A., 2010. A Survey on Lean Manufacturing Implementation in Malaysian Automotive Industry, International Journal of Innovation, Management and Technology, 1(4), 374-380.

Oehmen J. (Ed.), 2012. The Guide to Lean Enablers for Managing Engineering Programs, Joint MIT PMI INCOSE Community of Practice on Lean in Program Management

Sage, A. P., 1977. Interpretive Structural Modeling: Methodology for Large-Scale Systems, New York, NY: McGraw-Hill, 91-164.

Sharma, H. D., Gupta, A. D., Sushil, 1995. The objectives of waste management in India: a futures inquiry, Technological Forecasting and Social Change, 48(3), pp. 285-309.

Shrimali, A. K., Soni, V. K., 2017. A Review on Issues of Lean Manufacturing Implementation by Small and Medium Enterprises, International Journal of Mechanical and Production Engineering Research and Development (IJMPERD), 7(3), 283-300.

Shrimali, A. K., Soni, V. K. \& Pawar S. S., 2018. Interpretive Structural Modeling of identified Barriers to Lean Implementation in SMEs, 12th International Conference Quality Production Improvement- QPI 2018, ZABORZE near MYSZKÓW, POLAND, MATEC Web of Conferences 183, 01-08. DOI : https://doi.org/10.1051/matecconf/201818301008

Usta, S K., Asan, S. S., 2016. Analysis of Interactions among the Lean Implementation Barriers, Proceedings of Global Joint Conference on Industrial Engineering and Its Application Areas, Istanbul 34367, Turkey

Warfield, J. W., 1974. Developing interconnected matrices in structural modeling, IEEE Transactions on Systems, Men and Cybernetics, 4(1), 51-81.

Warfield, J. W., 1976. Societal Systems: Planning, Policy and Complexity, John Wiley \& Sons, Inc., New York, NY

Yamchello, H.T., Samin, R., Tamjidyamcholo, A. Beheshti, A., 2014. A Review of the Critical Success Factors in the Adoption of Lean Production System by Small and Medium Sized Enterprises. DOI: 10.4028/www.scientific.net/AMM.564.627

Zargun, S. \& Al-Ashaab, 2014. Critical Success Factors for Lean Manufacturing: A Systematic Literature Review. An International Comparison between Developing and Developed Countries, Advanced Materials Research, 845, 668-681. 